\title{
Key Issues in English for Specific Purposes in Higher Education. Yasemin Kirkgöz \& Kenan Dikilitaş (Eds.), Vol. 11. Switzerland: Springer International Publishing, 2018. 353 pp. ISBN 978-3-319-70213-1
}

\author{
Lilia Raitskaya \\ Moscow State Institute of International Relations (MGIMO University) \\ Correspondence concerning this article should be addressed to Lilia Raitskaya, MGIMO-University, 76 \\ Prospekt Vernadskogo, Moscow, Russian Federation, 119454.E-mail: 1.raitskaya@mail.ru
}

English for Specific Purposes (ESP) is an established and fast-developing discipline. ESP got a boost in the early 1960s, when it became integral to most university curricula.

The reviewed volume entitled 'Key Issues in English for Specific Purposes in Higher Education' was published in 2018 in the English Language Education Series of Springer International Publishing.

The book provides a panoramic analysis of the major trends in ESP and ESP's position in the foreign language learning continuum in English Medium Instruction (EMI) contexts.

The volume is divided into four parts, starting from an introductory chapter with a general overview of the field and Part I focusing on ESP materials design and development, progressing toward ESP teacher development, analyzing curricular issues in ESP courses, and ESP correlation with Content and Language Integrated Learning (CLIL) and EMI.

The introductory chapter 'Recent Developments in ESP/ EAP/ EMI Contexts' by the volume editors Y. Kirkgöz and K. Dikilitaş dwells upon the history of ESP, which arose after World War II as an approach to language teaching for academic or occupational needs of learners.

Kirkgöz and Dikilitaș successfully attempted to introduce the main concepts and current developments in ESP in the framework of English as the world's lingua franca and the new needs of learners of English in the globalized world. The authors underline that ESP is concerned with real communication rather than formal language use.

Kirkgöz and Dikilitaş delineate the emergence of new global phenomena (EMI and CLIL), underlining that each of the approaches bring different sets of outcomes for learners. The authors consider various

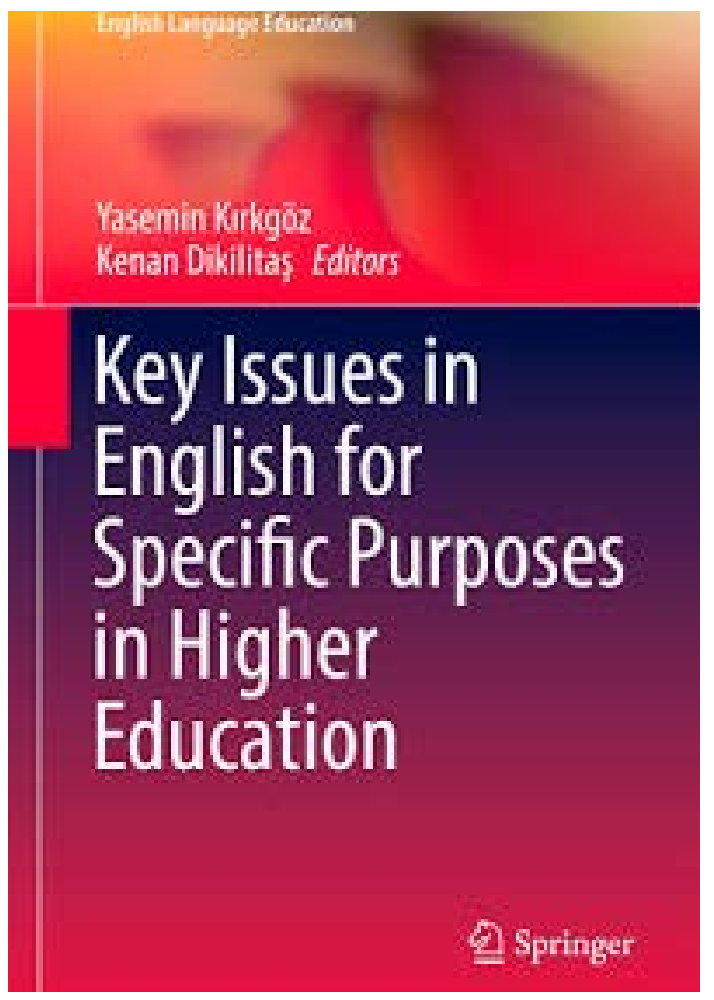

definitions (by M. Aguilar, J. Dearden, D. Graddol, and others) of ESP/EAP/EMI/ CLIL to show their scope and peculiarities. They highlight that ESP is also important in securing employment for university graduates.

The first strand of the book (Part I. Materials Design and Development in ESP) bifurcates into four empirical studies in the form of chapters. They deliver a deep and evidence-based analysis of material design processes and beliefs of experienced university ESP teachers; innovative ESP teaching practices for materials development; corpus-based approaches to the selection of medical vocabulary for an ESP course, 
and the selection of grammatical structures for ESP/ EAP materials.

The first chapter of Part I by H. Baştürkmen and A. Bocanegra-Valle reports a case study in university settings in Spain. The authors draw on data from indepth interviews with experienced ESP teachers. A generic problem typical of ESP materials, i.e. most of the published materials are not always relevant to the needs of their learners, was found and confirmed by all the interviewees. They underlined that most of the published materials are not always relevant to the needs of their learners.

The chapter 'Innovative ESP Teaching Practices and Materials Development' by F. L. Stoller and M. $S$. Robinson concentrates on the transition from general academic English to ESP. The authors use two approaches to ESP instruction (read-and-notice approach; read-analyze and write approach) as innovative teaching practice for chemistry majors, helping them make a transition to the ESP genres of their field of study.

The following two chapters are based on corpusbased approaches. The chapter 'Using a Corpus-Based Approach to Select Medical Vocabulary for an ESP Course' by B. Quero and A. Coxhead makes an interesting point about the use of multiple corpora and high-frequency word lists in a ESP course, using the twofold approach (corpus comparison and semantic rating scale). The authors suppose that the lexical component of any ESP course is a key to efficient meaning-focused and language-focused activities and fluency development.

In the chapter 'Selecting Corpus-Based Grammatical Structures for ESP/ EAP Materials', H. Farhady, K. Tavassoli, and F. Haghighi Irani cover an often ignored aspect of ESP, the selection of grammatical structures with reliance on a corpus of professional texts. The objective of the research is to bring to the fore the most significantly frequent grammatical structures. The research shows that, in addition to the use of diverse grammatical structures in 6 macro and 29 micro disciplines, many of them show a preference to a set of limited structures. The findings of the chapter urge ESP course developers to concentrate on introducing more frequent and common grammatical structures.

Part II entitled 'ESP Teacher Development' comprises five chapters and starts with a study on an innovative form of collaborative teacher development, Lesson Study. The form originates from Japan. It implies that a group of teachers share subject-specific and teaching content knowledge via the joint planning of a lesson, teaching a lesson to a control group in front of their colleagues, peer evaluation, teaching to another groups of students, and a final joint evaluation. The chapter by J. Norton highlights the potential of Lesson Study for ESP teachers to foster collaborative engagement and strengthen ESP practitioners' subject knowledge as well as increase their awareness of the student learning process.

T. Lehtonen, in the chapter headlined 'Practitioner Research as a Way of Understanding My Work: Making Sense of Graduates' Language Use', describes how research helps individual teachers grow professionally. The author highlights the supportive environment as a requisite for doing or following research. Although the findings of the chapter cannot be generalized due to the limitations of the study, they may be of help to ESP practitioners in self-development and gaining new insights into ESP.

The chapter 'Expanding Possibilities for ESP Practitioners Through Interdisciplinary Team Teaching' by T. Stewart attempts to define the place of ESP practitioners within academia. A special model called 'Collaborative Interdisciplinary Team Teaching' was used to reflect on the issue of the professional identity of ESP practitioners, whose professional profile is often perceived as quite low in academia due to the comparative novelty of the profession and it is still an unclear professional area. The latter is often referred to as the periphery of the curriculum. Stewart's model suggests a technology providing for collaborative work on an ESP course of ESP teachers with discipline specialists that enhances the professional status of ESP practitioners.

The chapter 'Perceptions of Students, Teachers and Graduates About Civil Aviation Cabin Services ESP Program: An Explanatory Study in Turkey' is based on data received via semi-structured interviews and pattern-coding. The findings reveal similarities in the perceptions of the participants (students, teachers, graduates) regarding the expectations, problems, and improvements in an ESP course (i.e. Aviation English Course).

Part III 'Curricular Issues in ESP' consists of five chapters. The first of them headlined 'Introducing Innovation into an ESP program: Aviation English for Cadets' presents a comprehensive analysis of the ESP course stakeholders (graduates, experts, instructors, and cadets), evaluating the New Turkish Air Force Academy Curriculum. The authors - M. Er and Y. Kirkgöz - show that aviation English curricula need to be constantly revised and updated to reflect the fact that aviation is a fast changing industry.

The next chapter entitled 'From EFL to EMI: Hybrid Practices in English as a Medium of Instruction in Japanese Tertiary Contexts' by N. Fujimoto-Adamson and J. Adamson explores the methodological aspects of teaching sociolinguistics to Japanese undergraduate students in EMI contexts. The research is based on teaching practices and evidence extracted from a collaborative autoethnographic account of the perceptions of the two practitioners concerning their professional practices connected with their shift into 
teaching content using EMI.

The chapter 'Fostering Active Learner Engagement in ESP Classes' written by N. Mačianskienè and V. Bijeikienè touches upon an important aspect of teaching ESP that urges learners to be actively involved in the learning process. The study follows the Mixed Method Approach and analyzes ESP courses in respect to course descriptions, learner needs, ESP course methods and activities, and opportunities. Mačianskienė and Bijeikienè suggest that ESP courses can be enhanced with a learner-centered approach and active learning and teaching methods, the pillars of ESP practitioners' practice.

Another chapter 'Are We Really Teaching English for Specific Purposes, or Basic English Skills? The Cases of Turkey and Latvia' explores ESP as an essential subfield of English language education, ranging from academic to professional and vocational areas. The authors handle the touchy subject of insufficient resources, lack of skilled teachers, and other challenges and problems an ESP course may face. The chapter is based on a study carried out in two universities in Turkey and Latvia to find out the teachers' evaluation of their ESP practice. The findings demonstrate that the obstacles and limitations related to poor planning, overcrowded classrooms, students' low level or lack of basic English skills, and others often prevent students from going beyond a general English course. The authors suggest some improvements for overcoming the existing deadlock.

The final chapter of Part III headlined 'Listening Comprehension Strategies of EMI Students in Turkey' discusses the peculiarities of EMI in higher education, with a listening comprehension strategy survey at the core of the research which aims to reveal the preferences of EMI students when listening to their lecturers in English. The strategies turn out to depend on gender, context, major, and other aspects. The study also found that there is a correlation between higher student scores and better comprehension.

Part IV entitled 'ESP, CLIL and EMI' covers issues of interrelations and overlappings of the basic approaches in English language instruction. The chapter 'ESP/ EAP in University Programs in a Nontarget Language Community - Issues and Challenges' by J. O’Dwyer and H. Handan Ath looks into the strengths and weaknesses related to EMI in universities in nonEnglish speaking countries. O'Dwyer and Handan Ath outline the complexity of the system that students have to enter while sometimes at an elementary level. Concerns are also expressed about lecturers with little EMI experience and other negative factors. The authors discuss the role of language instructors in EMI contexts and the training of content and language teachers.
I. Alonso-Belmonte and M. Fernández- Agüero in their research 'The $C$ of Cognition in CLIL Teacher Education: Some Insights from Classroom-Based Research' aim to consider foreign language (FL) practice in state bilingual schools in Spain in the CLIL context with the goal of mapping the key classroom tasks to encourage critical thinking. Their findings show that, at present, the prevailing practice boils down to loworder thinking skills. Thus, the research confirms the discord within the CLIL teaching community over the adequacy of CLIL routines in the primary classrooms and calls for a broader discussion about further CLIL application.

The sensitive issue of widening EMI contexts with more disciplines delivered in English is studied by J. Dearden in the chapter 'The Changing Roles of EMI Academics and English Language Specialists'. As universities worldwide seek to become internationalized by attracting more foreign students and giving local students a competitive edge on the labour market, they urge academics and lecturers to teach their academic subjects in EMI settings. The transition cannot be smooth and problem-free, as subject specialists do not tend to be ready and willing to teach in English. As Dearden underlines 'going EMI' for universities implies structural changes (a new language policy; training and re-training, etc.) and takes time.

The final chapter of Part IV and the volume 'Quality Assurance of EAP Programs in the EMI Context' by D. F. Staub scrutinizes the mechanisms assuring compliance with high quality standards for EAP programs. Staub indicates that today's systems of quality assurance often lack expertise and knowhow. That leads to failures or inadequate depth of assessments. Staub suggests using some established accreditation model implies getting the involved staff members well prepared for possible variations within the framework. Thus, professional development enhances the efficiency of quality assurance.

The book makes a significant empirical contribution to ESP teaching and learning. Some of the chapters are too narrow-focused, and their findings cannot be generalized for the ESP field. But they prompt the readers to revise their attitudes and reflect on some ESP challengers. Overall, this is a well-researched and well-designed book. The authors have successfully presented a comprehensive and insightful narrative on the key trends in ESP and the related realms of EMI, CLIL, and EAP.

The potential audience of this volume includes researchers, postgraduate and graduate students majoring in the field of applied linguistics, as well as university teachers and ESP practitioners. 